\section{Science Information}

Proceedings of the Conference on Training Science Information Specialists, October 12-13, 1961, April 12-13, 1962, Georgia Institute of Technology, Atlanta, Georgia, sponsored by the National Science Foundation, Dorothy M. Crosland, General Chairman. [Atlanta: Georgia Institute of Technology, 1962] 139p. Apply.

The hard and intelligent efforts of Dorothy Crosland and the funds of the National Science Foundation have combined to bring together in these comparatively few pages substantial facts on a score of training programs in action, or on launching stages, to educate personnel for current and anticipated science information dissemination needs. Some programs described are of curricular nature and are from a wide range of institutions, both as to geography and educational character: Drexel in the East to California, Georgia Tech to Illinois, with intermediates like Lehigh and Tennessee. Two presentations discuss a variety of short courses that have been given on information storage and retrieval and on the logic of mechanizing information. Brief presentations cover education of European information specialists, based on a series of visits to Europe in 1962.

It is obvious that coverage only of highlights has been attempted in these proceedings. Typical presentations average four pages, so that general goals, names of courses with no course descriptions, and brief justifications are all that can be given. Since the decisions as to what programs were to be described were rigorously made, and since their descriptions are by those top individuals who are involved in teaching, this distillation of science information training's trends and achievements in this country is a distinct contribution to understanding the "state of the art" and to estimating its immediate future.

More than fifty persons attended one or both conferences, and after the presentations engaged in extended periods of discussion and debate. A report of more than twenty pages has been compiled from recordings, which report adequately reemphasizes the variety of needs and the problems of definitions and acceptances which must be evolved. The actual debates that occurred, sometimes with heat and occasionally with light, are for the most part edited out. Tact is here probably the better part of reporting. But no doubt is left with the conscientious reader that developing the personnel which our science and technology documentation will require is still an unsolved problem and that no monolithic structure for its solution was forged by these participants. No one, however, who really wants to know the elements of those difficulties and of the several developing solutions can find a briefer and more authoritative presentation than in these few pages.

Some special notice is in order about the "threat" to librarians and to their status which some librarians and library educators feel exists in the "science information explosion." In these Proceedings, Appendix I, p. 114-15, are printed definitions which list what these worriers may deem to be a "hierarchy" of position titles going from the bottom of a totem pole to the top: librarian, special librarian, science librarian, technical literature analyst, information scientist. As definitions they are at least a studied beginning, though they have already provoked some interesting challenge from our English cousins. Also "guild" conscious library school graduates at work for scientists have correctly stressed how unprofessional their users have found certain existing samples of technical literature analysis, not to say how nebulous all of us admit most information science now is.

One thing was clear at the Georgia Institute conferences. No devaluation of any discipline, including librarianship, was intended. If jobs in technical literature analysis or in information science develop, they will be new jobs, inevitably additional jobs. As they open up, each person who takes on such work will have to give up his present specialty. If he has been a linguist, it will mean essentially giving up linguistics; if a mathematician, giving up mathematics; if a computer scientist, giving up computer science; if a librarian, giving up librarianship. If these persons only build upon their present specialties to pass soon thereafter into the new ones, let us not therefore assume the demise of linguistics, mathematics, 
computer science, or librarianship. All listed disciplines will continue doing what they have done, doing more, and surely doing both better.

A number of library schools long since took pioneering steps in adding to their curricula courses in science and engineering literature and bibliography, as well as in the literature and bibliography of other fields. It was evident at the conferences that library school heads are openminded about additional training to be offered to their science-interested enrollees. But with such a great need for librarians, the heads rightly were not in favor of diminishing any of their present programs. What the conferences clearly indicated is that more, and more widely varied, training is needed. Programs to do this were prescribed, some as definite proposals. Since the conference, two elaborate ones known to the reviewer have actually been formalized: the first at Drexel, well coordinated with its library school; a second at Georgia Tech as a "School of Information Science" administratively approved to start in September 1963. These conferences may well turn out to be as seminal as the National Science Foundation had hoped, and this little book may turn out to be a truly significant document for all concerned.-J. H. Moriarty, Purdue University Libraries.

\section{Microphotography}

Enlarged Prints From Library Microforms. By William R. Hawken. (Library Technology Project Publication No. 6) Chicago: American Library Association, 1963. 131 p. \$4.

Microphotography has become an accepted communications medium for establishing information systems in libraries. In many cases output by display on the microfilm reader screen is sufficient for the needs of the user. There is, however, a tendency (encouraged by the increasing use of office copiers) for the scholar to demand hardcopy output from the micro-reproduction system. As a result, there are now about twenty different models of microform readerprinters available. These make it possible for the user to examine his microcopy on the reader screen and immediately receive paper prints of the pages he wants without sending the microform to a darkroom or commercial laboratory. Most of these machines are designed for $16 \mathrm{~mm}$ microfilm and aperture cards (e.g., IBM cards with a window holding a frame of $35 \mathrm{~mm}$ microfilm), forms of microfilm that are infrequently found in most libraries.

In this volume Mr. Hawken has limited his full evaluation to those eight models that will handle the microforms $(35 \mathrm{~mm}$ ribbon microfilm, $3 \times 5$ inch microcard, and $6 \times 9$ inch microprint) usually found in American libraries. These are: Filmac 100, Filmac 200-R, Filmac 300, Documat, Rollacopy/ Micromate, Universal (French), Microcard Copier, and Ross Microreader (English). Each machine was tested under conditions simulating those to be found in libraries and with microforms of originals common to most libraries. The performance characteristics, advantages, disadvantages, capabilities, and limitations of each example are considered and described, with many excellent and helpful illustrations. Some models that work well with microfilm of business records, and others that perform satisfactorily with engineering drawings in Filmsort cards, did not prove successful with library materials. A few of them showed poor design and manufacture. No machine came through the test with a perfect record. The nearest contender for a seal of approval was the Filmac 300 , but as its price is $\$ 3,600$ it will be beyond the range of most libraries.

The introductory chapters on the fundamentals of reader-printers and processes for rapid print production, and the chapter on various miscellaneous methods of print production, are well worth study by all librarians who are considering activity in this problem-filled field. The closing chapter of summation (which includes brief notes on some ten models in addition to the eight studied) is required reading for all potential users, as well as producers of current models and those planning to get into this field. There is information of value for all sorts of librarians; even the bibliophile will be interested in the choice of an example (figs. 56 and 57) to show the unevenness of illumination resulting in poor print-out of 